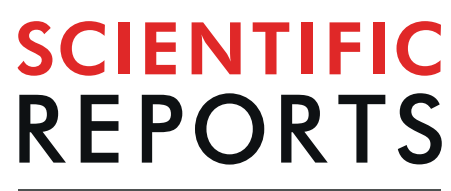

natureresearch

\title{
CD44/CD133-Positive Colorectal Cancer Stem Cells are Sensitive to Trifluridine Exposure
}

\author{
Kenta Tsunekuni $i^{1,2,3}$, Masamitsu Konno $\mathbb{1}^{4}$, Naotsugu Haraguchi ${ }^{1}$, Jun Koseki ${ }^{2}$, \\ Ayumu Asai ${ }^{1,2,4}$, Kazuaki Matsuoka ${ }^{3}$, Takashi Kobunai ${ }^{3}$, Teiji Takechi $\mathbb{1}^{3}{ }^{3}$, Yuichiro Doki ${ }^{1}$, \\ Masaki Mori ${ }^{1,5^{*}}$ \& Hideshi Ishii ${ }^{1,2^{*}}$
}

Cancer stem cells (CSCs) are involved in metastatic colorectal cancer recurrence, but no effective therapy targeting these cells is currently available. Because trifluridine (FTD)/tipiracil therapy is used for refractory colorectal cancer, we sought to determine whether FTD is effective against CSC-like cells. $\mathrm{CD} 44^{+} \mathrm{CD} 133^{+}$high-expressing and other populations of human DLD-1 colon cancer cells were separately isolated through fluorescence-activated cell sorting. The sphere-forming activity of each population and the anti-sphere-forming effects of FTD and fluorouracil (5-FU) on CD44 ${ }^{+}$CD133 ${ }^{+}$ cells were then measured. CD44 ${ }^{+}$CD133 ${ }^{+}$DLD-1 cells formed substantially more spheres than other cells. Moreover, treating CD44 ${ }^{+}$CD133 ${ }^{+}$DLD- 1 cells with subtoxic concentrations of FTD $(1 \mu M)$ inhibited sphere formation, and this was superior to the effect of subtoxic concentrations $(1 \mu \mathrm{M})$ of 5-FU. The associated inhibition rates for FTD and 5-FU were $58.2 \%$ and $26.1 \%$, respectively. Further, $\mathrm{CD}_{44}{ }^{+} \mathrm{CD} 133^{+}$DLD-1 cells expressed higher levels of thymidine kinase 1 , which is responsible for FTD phosphorylation, than DLD-1 cells, and FTD was incorporated into the DNA of CD44+CD133+ DLD-1 cells. Thus, our data show that FTD treatment is effective against CSC-like cells and might be applied as CSC-targeting chemotherapy for tumor subtypes with high CD44 and CD133 expression.

Cancer stem cells (CSCs) represent a subpopulation of cells that displays stem cell characteristics and this subset influences tumorigenesis ${ }^{1}$; further, CSCs exhibit diverse cancer-promoting properties such as self-renewal ${ }^{2}$, chemoresistance $^{3}$, and metastatic potential ${ }^{4,5}$. Accordingly, it is considered that CSCs adversely affect patient outcome, but active anti-cancer agents targeting these cells are not currently available in clinical settings.

For the identification of CSCs, one of the first markers of stemness used was the transmembrane glycoprotein CD133, also known as prominin- $1^{1,2}$, for which expression strongly predicts poorer prognosis; specifically high CD133 levels are inversely correlated with the 5-year overall survival and disease-free survival rates in patients with cancers ${ }^{6}$ including colorectal cancer (CRC). Another putative CSC marker is the cell-surface glycoprotein $\mathrm{CD} 44^{7}$, which was reported to be an adhesion molecule expressed in cancer stem-like cells ${ }^{8}$. The combined analysis of these putative co-CSC markers, namely CD133 and CD44, was found to improve the discrimination of low- and high-risk cases of CRC, as compared to that with single-marker analyses ${ }^{9}$. Moreover, patients with CD44- and CD133-positive gastric cancer were found to have a poorer survival rate than patients with CD44- and CD133-negative disease ${ }^{10}$.

For CRC, the standard chemotherapy used globally is fluoropyrimidine-, oxaliplatin (L-OHP)-, and irinotecan-based combination regimens with anti-EGFR and anti-VEGF treatment for first-line and second-line settings ${ }^{11}$. In the third- or later-line settings, regorafenib was approved and has been used ${ }^{12}$ in the United States. In addition, The Food and Drug Administration (FDA) has approved pembrolizumab or nivolumab for CRC patients with microsatellite instability-high (MSI-H) tumours and larotrectinib for CRC patients with tumours with neurotrophic tropomyosin receptor kinase (NTRK) fusions in the US. Trifluridine (FTD)/tipiracil (TPI),

\footnotetext{
${ }^{1}$ Department of Gastrointestinal Surgery, Osaka University Graduate School of Medicine, Osaka, 565-0871, Japan. ${ }^{2}$ Department of Medical Data Science, Osaka University Graduate School of Medicine, Osaka, 565-0871, Japan. ${ }^{3}$ Present address: Translational Research Laboratory, Taiho Pharmaceutical Co., Ltd., Tokushima, 771-0194, Japan. ${ }^{4}$ Department of Frontier Science for Cancer and Chemotherapy, Osaka University Graduate School of Medicine, Osaka, 565-0871, Japan. ${ }^{5}$ Present address: Department of Surgery and Science, Graduate School of Medical Sciences, Kyushu University, Fukuoka, 812-8582, Japan. *email: mmori@gesurg.med.osaka-u.ac.jp; hishii@gesurg.med. osaka-u.ac.jp
} 


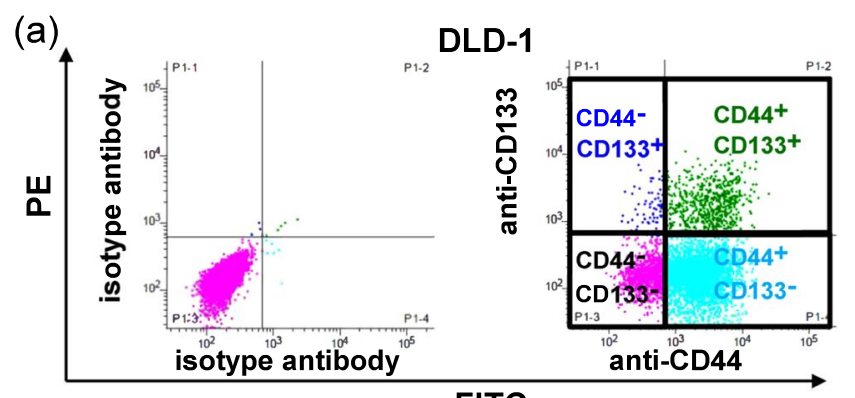

(b)

\section{FITC}

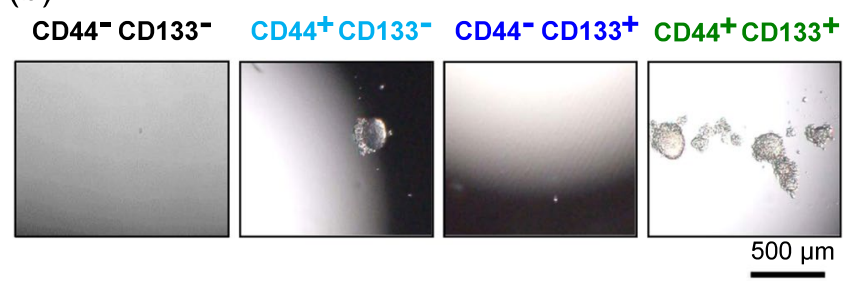

(c)

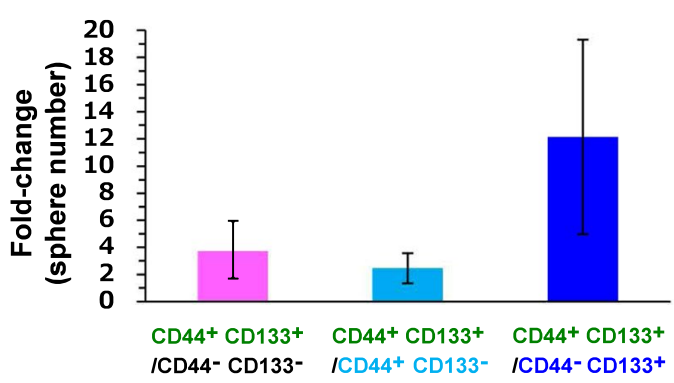

Figure 1. Formation of stem cell spheres after seeding sorted $\mathrm{CD} 44^{+} \mathrm{CD} 133^{+}, \mathrm{CD} 44^{-} \mathrm{CD} 133^{-}, \mathrm{CD}_{4} 4^{-}$ $\mathrm{CD} 133^{+}$, and $\mathrm{CD} 44^{+} \mathrm{CD} 133^{-}$cells of the colorectal cancer (CRC) DLD-1 cell line. (a) Left column shows isotype control and right column shows anti-CD44-FITC and anti-CD133-PE antibody double-staining of DLD-1 cells. The quadrants comprising each population are defined as $\mathrm{CD} 44^{-} \mathrm{CD} 133^{+}, \mathrm{CD} 44^{+} \mathrm{CD}_{133^{+}}$, $\mathrm{CD} 44^{-} \mathrm{CD} 133^{-}$, and $\mathrm{CD} 44^{+} \mathrm{CD} 133^{-}$, respectively. (b) Representative sphere images of $\mathrm{CD} 44^{-} \mathrm{CD} 133^{-}$cells, $\mathrm{CD} 44^{-} \mathrm{CD} 133^{+}$cells, $\mathrm{CD} 44^{+} \mathrm{D} 133^{-}$cells, and $\mathrm{CD} 44^{+} \mathrm{CD} 133^{+}$cells are shown from the left to right column, respectively. (c) Sphere numbers determined for CD $44^{-} \mathrm{CD} 133^{-}, \mathrm{CD} 44^{-} \mathrm{CD} 133^{+}, \mathrm{CD} 44^{+} \mathrm{D} 133^{-}$, and $\mathrm{CD} 44^{+}$ $\mathrm{CD} 133^{+}$DLD-1 cells. Data points represent means $\pm \mathrm{SD}(\mathrm{n}=6)$.

also known as TAS-102, was also tested for its ability to treat patients with metastatic CRC who were previously treated with chemotherapy based on drugs such as fluoropyrimidine, L-OHP, and irinotecan, among others, and this therapy was found to improve overall survival ${ }^{13}$. After receiving the results of this clinical trial, FTD/TPI was approved and has been used globally in regions such as Japan, the EU, and the US in third- or later-line settings. FTD/TPI is an oral combination drug consisting of FTD, a thymidine analogue, and TPI, a thymidine phosphorylase inhibitor that improves the bioavailability of $\mathrm{FTD}^{14}$. Despite the initial success of this agent, its effect on CSC populations was not previously known. Because FTD/TPI is used for refractory CRC, which is considered a CSC-enriched phenotype ${ }^{15}$, we hypothesised that FTD might effectively target CSC-like cells. Here, we investigated whether this drug is effective against CD44- and CD133-highly-expressing $\left(\mathrm{CD} 44^{+} \mathrm{CD} 133^{+}\right) \mathrm{CRC}$ cells that possess CSC-like properties.

\section{Results}

Isolation of $\mathrm{CD}_{4} 4^{+} \mathrm{CD} 133^{+}, \mathrm{CD}_{4}{ }^{+} \mathrm{CD} 133^{-}, \mathrm{CD}_{4}-\mathrm{CD}^{-} 33^{+}$, and $\mathrm{CD}_{4} 4^{-} \mathrm{CD}_{133^{-}}$cells and examination of their sphere-formation ability. To delineate CD44 and CD133 expression in the DLD-1 CRC cell line, we used flow cytometry to measure the expression of these surface molecules after double-staining with anti-CD44-FITC and anti-CD133-PE antibodies. Figure 1a shows DLD-1 flow cytometry data collected after staining and sorting. These cells showed a distribution of CD44 and CD133 expression, with a $\mathrm{CD} 44^{+} \mathrm{CD} 133^{+}$population of $11.3 \%$, a CD $44^{+} \mathrm{CD} 133^{-}$population of $65.3 \%$, a CD $44^{-} \mathrm{CD} 133^{+}$population of $2.1 \%$, and a CD $44^{-} \mathrm{CD} 133^{-}$population of $21.3 \%$. Cells were isolated using FACS and then transferred into serum-free DMEM/F-12; the isolated CD $44^{+} \mathrm{CD} 133^{+}, \mathrm{CD}_{4} 4^{+} \mathrm{CD} 133^{-}, \mathrm{CD}_{4} 4^{-} \mathrm{CD} 133^{+}$, and $\mathrm{CD} 44^{-} \mathrm{CD} 133^{-}$ cells were then used for sphere-formation assays to evaluate their stem cell-like properties. Sphere formation in suspension culture is recognised as the prominent characteristic of CSCs and can be used for in vitro measurements of CSC function. Here, culturing these cells in serum-free medium in low-adhesion 96-well plates revealed that sphere formation ability was considerably higher in the $\mathrm{CD} 44^{+} \mathrm{CD} 133^{+}$population compared to that in the $\mathrm{CD}_{4} 4^{-} \mathrm{CD} 133^{-}, \mathrm{CD}_{4}{ }^{+} \mathrm{CD} 133^{-}$, and $\mathrm{CD} 44^{-} \mathrm{CD} 133^{+}$populations (fold-changes for $\mathrm{CD} 44^{+} \mathrm{CD} 133^{+}$sphere 
(a)
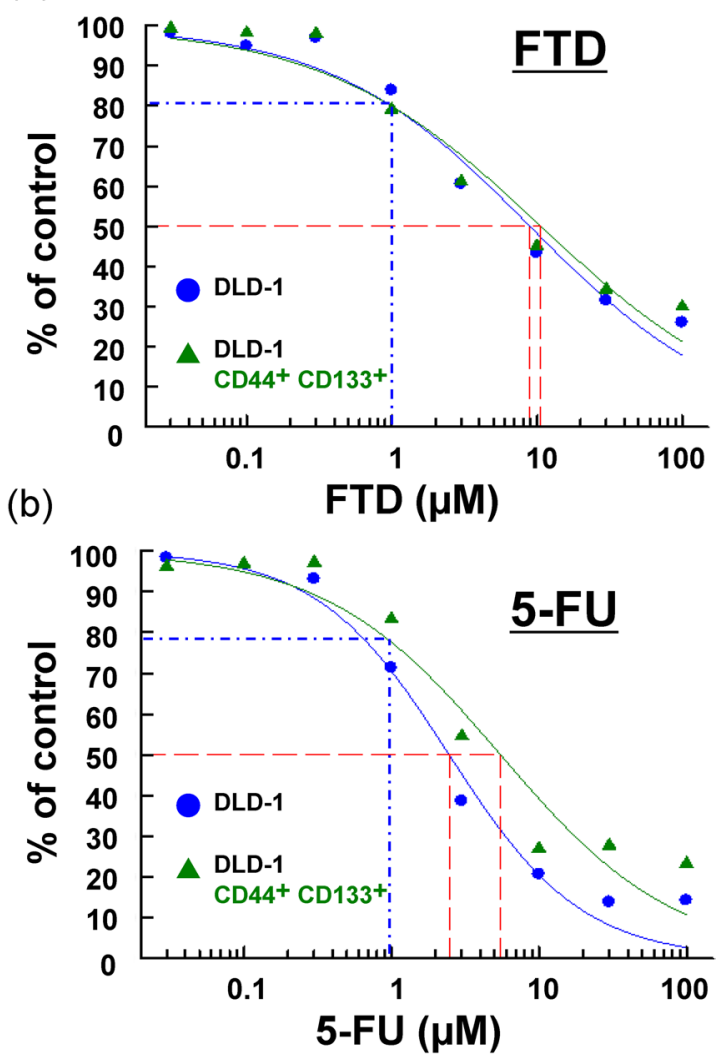

Figure 2. Antiproliferative effect of trifluridine (FTD) on isolated CD $44^{+} \mathrm{CD} 133^{+}$cells. Sorted CD $44^{+} \mathrm{CD} 133^{+}$ cells (shown in Fig. 1) and unsorted DLD-1 cells shown here were cultured with various concentrations of FTD (a) and fluorouracil (5-FU) (b). Cell viability was determined using crystal violet staining based on at least three independent experiments. Data points represent means $\pm S D(n=3)$. Blue dashed line represents estimated viability determined for $1 \mu \mathrm{M}$ FTD and 5-FU; values were estimated using a fitting curve in the logistic model. Red dashed line represents estimated $\mathrm{IC}_{50}$ values.

numbers relative to that with other populations were $3.7,2.5$, and 12.1 respectively; Fig. $1 \mathrm{c}$ ). In addition, sphere sizes were larger in the $\mathrm{CD} 44^{+} \mathrm{CD}_{133}{ }^{+}$population than in other populations (Fig. 1b). The results indicate that $\mathrm{CD} 44^{+} \mathrm{CD} 133^{+}$populations exhibit the most stem cell-like properties compared to other populations.

Anti-proliferative effect of FTD on isolated $\mathrm{CD}_{4} 4^{+} \mathrm{CD} 133^{+}$cells. We next investigated whether FTD was effective against CSC-like CD $44^{+} \mathrm{CD} 133^{+}$DLD-1 cells. The antiproliferative effect of FTD on these cells was investigated by performing cytotoxicity tests with crystal violet staining on CD $44^{+} \mathrm{CD} 133^{+}$(depicted in Fig. 1a) and unsorted DLD-1 cells. After $72 \mathrm{~h}$ of treatment, FTD was effective against both cell populations, with the calculated $\mathrm{IC}_{50}$ values being 10.7 and $8.9 \mu \mathrm{M}$, respectively (Fig. 2a). In contrast, resistance toward 5-FU was higher for $\mathrm{CD} 44^{+} \mathrm{CD} 133^{+}$DLD-1 cells $\left(\mathrm{IC}_{50}=5.5 \mu \mathrm{M}\right)$ than for unsorted DLD-1 cells $\left(\mathrm{IC}_{50}=2.5 \mu \mathrm{M}\right)$; the fold-change in $\mathrm{IC}_{50}$ was 2.2 for 5 -FU and 1.2 for FTD (Fig. 2b). These results indicate that FTD is effective against a CD44 ${ }^{+}$ $\mathrm{CD}_{133}{ }^{+}$CSC-like population.

FTD treatment and sphere-formation activity. Next, to investigate the effect of FTD treatment on the sphere-forming capacity of CD $44^{+} \mathrm{CD} 133^{+} \mathrm{DLD}-1$ cells, we performed sphere-formation assays on cells treated with FTD and 5-FU (Fig. 3a,b). As compared to the number of spheres in control samples (DMSO treatment), fewer spheres were present in cells treated with FTD at $1 \mu \mathrm{M}$, but not in those treated with 5 -FU at $1 \mu \mathrm{M}$ (Fig. 3b). Both drug concentrations used in this study were sub-toxic (estimated viability determined in the presence of FTD and 5-FU based on cytotoxicity assays with crystal violet staining at $72 \mathrm{~h}$ was $79.9 \%$ and $77.6 \%$, respectively; both values were estimated based on a fitting curve in the logistic model). Thus, the efficacy of FTD was greater than that of 5-FU in terms of sphere-formation activity, although the cytotoxic effects of both drugs at $1 \mu \mathrm{M}$ were comparable.

Thymidine kinase 1 expression in $\mathrm{CD} 44^{+} \mathrm{CD}_{133}{ }^{+}$cells. FTD was previously reported to be phosphorylated by thymidine kinase 1 (TK1) and incorporated into $\mathrm{DNA}^{16}$. In addition, FTD incorporation into DNA is the main mechanism underlying its anti-tumour effects ${ }^{17}$. Thus, to further investigate the inhibitive effect of FTD on the sphere-forming capacity of CD $44^{+} \mathrm{CD} 133^{+}$DLD- 1 cells, we performed real-time PCR analysis to 
(a)

$$
\begin{gathered}
\text { DLD-1 } \\
\text { CD } 44^{+} \text {CD } 133^{+}
\end{gathered}
$$
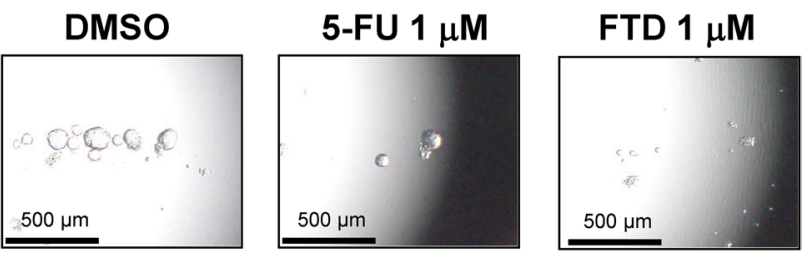

(b)

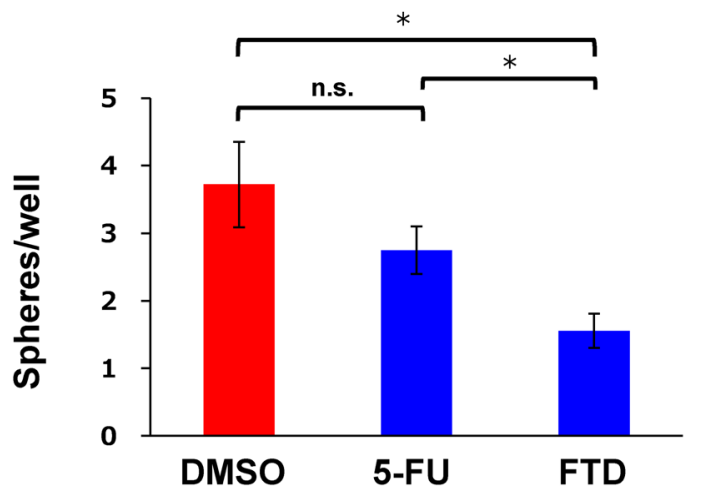

Figure 3. FTD efficacy toward sphere-forming activity of $\mathrm{CD} 44^{+} \mathrm{CD} 133^{+}$cells. Sphere culture was performed using the $\mathrm{CD}_{4} 4^{+} \mathrm{CD} 133^{+}$population of the DLD-1 cell line. (a) Images of cell spheres treated with DMSO (Control), $1 \mu \mathrm{M} 5$-FU, and $1 \mu \mathrm{M}$ FTD; (b) Respective sphere numbers. Data points represent means \pm SD $(\mathrm{n}=6)$; Student's $t$-test, $* P<0.05$, n.s.: not significant.

determine the expression of TK1 using CD $44^{+}$CD $133^{+}$DLD- 1 cells and unsorted cells. As compared to that in unsorted DLD-1 cells, CD $44^{+}$CD133 ${ }^{+}$DLD-1 cells exhibited 2.3-fold increased TK1 expression (Fig. 4a).

FTD incorporation into the DNA of CD44 ${ }^{+} \mathrm{CD}_{133^{+}}$spheres. Finally, because TK1 was highly expressed in $\mathrm{CD} 44^{+} \mathrm{CD} 133^{+}$DLD-1 cells, we hypothesised that FTD could be incorporated into the DNA of these cells to inhibit their sphere-forming activity. Hence, we investigated the incorporation of FTD into the DNA of CD $44^{+} \mathrm{CD} 133^{+}$DLD-1 spheres. Detectable spheres were formed approximately 10 days after cell seeding. Further, after sorting CD $44^{+} \mathrm{CD} 133^{+}$DLD- 1 cells, the expression of both markers was maintained for 14 days (data not shown). Therefore, the genomic DNA of CD $44^{+} \mathrm{CD} 133^{+} \mathrm{DLD}-1$ spheres treated with $1 \mu \mathrm{M}$ FTD was isolated after 11 days, and this compound was detected by dot plot analysis using an FTD-cross-reacting anti-BrdU antibody ${ }^{18}$. Indeed, FTD was detected in the DNA of treated CD $44^{+}$CD133 ${ }^{+}$DLD- 1 spheres but not in the DNA of DMSO (control)-treated cells (Fig. 4b). This result indicates the contribution of FTD DNA-incorporation to its inhibitory effect on sphere-forming activity.

\section{Discussion}

In this study, we showed that $\mathrm{CD} 44^{+} \mathrm{CD} 133^{+}$DLD-1 cells exhibit the highest sphere-forming activity compared to $\mathrm{CD} 44^{-} \mathrm{CD} 133^{-}, \mathrm{CD} 44^{+} \mathrm{CD} 133^{-}$, and $\mathrm{CD} 44^{-} \mathrm{CD} 133^{+} \mathrm{DLD}-1$ cells, as reported previously for HCT-116 cells ${ }^{19}$. Here, isolated CD $44^{+}$CD $133^{+}$DLD-1 cells also exhibited increased resistance to 5-FU but not FTD as compared to that in unsorted DLD-1 cells based on a sensitivity test (Fig. 2a,b); moreover, FTD but not 5-FU treatment inhibited sphere-forming activity against these cells at a subtoxic concentration (Fig. 3a,b). These results indicated that FTD is effective against CSC-like cells, unlike 5-FU.

In a previous study, a CSC-like CD44-stably expressing MKN28 gastric cancer cell line was reported to have resistance to cisplatin and docetaxel $^{8}$ and CSC-like CD133-highly expressing primary colon cancer cells were reported to exhibit resistance to 5-FU and L-OHP ${ }^{3}$. Among DLD-1 cells, a CD133-expressing population was also found to be more resistant to 5-FU treatment compared to that with unsorted cells ${ }^{20}$. Further, 5-FU treatment was found to induce an increase in CD44 and CD133 expression, and CD44- and CD133-highly-expressing cells were reported to exhibit stem cell-like properties and resistance to 5 -FU ${ }^{15}$. In CSC-like cells, one drug resistance mechanism, with respect to 5-FU and other drugs, was reported to be partially dependent on TRAIL-induced death cell, which was inhibited by the expression of anti-apoptotic proteins ${ }^{3}$. CSC-like CD133 ${ }^{+}$cells are also enriched in anti-apoptotic proteins and are resistant to 5 -FU ${ }^{21}$. Our study showed that unlike 5-FU, FTD was effective against $\mathrm{CD} 44^{+} \mathrm{CD} 133^{+}$cells. Hence, another mechanism underlying the response of CSC-like cells (such as $\mathrm{CD} 44^{+} \mathrm{CD} 133^{+}$cells) to FTD treatment, compared to that associated with 5 -FU, is suggested. Poorly-differentiated human hepatocellular carcinoma cells, which present an overlapping 
(a)

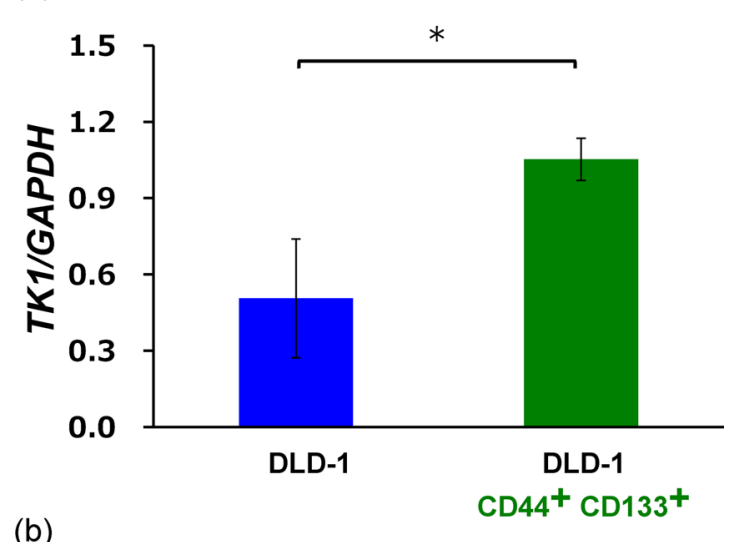

Dot blot analysis; genomic DNA from sphere

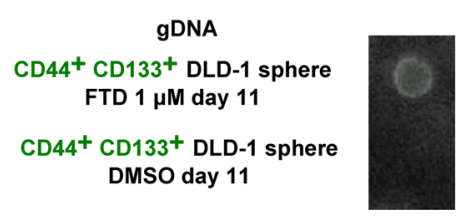

Figure 4. Thymidine kinase (TK1) expression and FTD incorporation in CD44+ CD133+ DLD-1 cells. (a) TK1 expression in CD $44^{+} \mathrm{CD} 133^{+}$cells. TK1 levels in DLD- 1 cells and CD $44^{+} \mathrm{CD} 133^{+} \mathrm{DLD}-1$ cells were assayed using qRT-PCR and normalized against GAPDH levels. Data points represent means \pm SD of triplicate determinations; Student's $t$-test, $* P<0.05$. (b) Dot plot analysis of FTD incorporation into the genomic DNA of CD $44^{+} \mathrm{CD}_{133^{+}} \mathrm{DLD}^{-1} 1$ spheres. CD $44^{+} \mathrm{CD} 133^{+}$DLD-1 cells were cultured in the presence of $1 \mu \mathrm{M}$ FTD or DMSO for 11 days in sphere-formation assay conditions and genomic DNA was purified. Purified DNA (1 ng) was denatured with an alkaline solution $(0.1 \mathrm{~N} \mathrm{NaOH})$, spotted onto a Hybond- $\mathrm{N}^{+}$membrane, and blotted with anti-BrdU antibodies.

stem cell-like phenotype with CSCs, have been reported to show the upregulated expression of pyrimidine metabolism-associated rate-limiting enzymes including $\mathrm{TK} 1^{22}$. In addition, CD44 expression is positively correlated with TK1 expression in triple negative breast cancer ${ }^{23}$. Moreover, TK1 mRNA was found to be upregulated in CD133-expressing human embryonic stem cells ${ }^{24}$. Because TK1 catalyses FTD phosphorylation ${ }^{16}$, it might be readily incorporated into the DNA in TK1-upregulated CSC-like populations. In this study, TK1 mRNA expression was higher in CD $44^{+}$CD133 ${ }^{+}$DLD-1 cells than in other populations (Fig. 4a), and indeed, FTD was incorporated into the DNA of CD $44^{+} \mathrm{CD}_{133^{+}}$DLD-1 spheres (Fig. 4b). FTD incorporation into the DNA of CSC-like cells might explain the anti-sphere forming activity of FTD toward 5-FU-resistant CSC-like spheres. Although CSC-like cells could be enriched in anti-apoptotic proteins, incorporation of the nucleotide analogue FTD into the DNA might provoke the interruption of DNA replication and delay the self-renewal of CSC-like cells. As a consequence, a preferential antiproliferative effect might be sustained in CSC-like cells (Fig. 5).

There are several limitations to this study. First, we used only DLD-1 cells, which were associated with the highest sorting efficacy for both $\mathrm{CD} 44^{-} \mathrm{CD} 133^{-}$and $\mathrm{CD} 44^{+} \mathrm{CD} 133^{+}$populations among three cell lines tested, also including HCT-116 and RKO cells (data not shown), to determine the efficacy of FTD toward CD44 ${ }^{+}$ CD133 ${ }^{+}$CRC cells. Moreover, our study showed that FTD exerted anti-sphere-forming activity toward CSC-like $\mathrm{CD}_{4} 4^{+} \mathrm{CD} 133^{+}$cells. However, these results are based only on in vitro experiments and therefore must be confirmed using in vivo assays and clinical studies. Accordingly, to investigate FTD efficacy in CSC-like CD44 ${ }^{+}$ $\mathrm{CD}_{133^{+}}$cells, we are planning an in vivo serial transplantation study to evaluate whether it can decrease tumorigenic capacity.

Despite the limitations, our study indicated for the first time that unlike other anti-cancer drugs, FTD might be effective against CSC-like cells expressing high levels of CD44 and CD133. These effects on CSC-like cells might explain the observed improvement in overall survival in patients treated with FTD/TPI in the clinical setting ${ }^{13}$. For gastric cancer, FTD/TPI has been used to treat patients with heavily-pre-treated metastatic gastric/ gastroesophageal junction (GEJ) cancers who have progressed or are intolerant to previous lines of therapy, and this was found to improve overall survival ${ }^{25}$. In gastric cancer, CD44 and CD133 were also reported to be relevant to chemoresistance ${ }^{26}$. Therefore, similarly, the improvement in overall survival could be due to the efficacy of FTD against CSC-like cells exhibiting high CD44 and CD133 expression and might be applicable for GEJ, as well as CRC. In addition, a similar response rate between FTD/TPI + bevacizumab and capecitabine + bevacizumab was confirmed in the TASCO-1 clinical trial conducted based on a first-line setting ${ }^{27}$; thus, the possibility that this drug might also be useful in an adjuvant setting (stem-like cell killing effect) should also be considered. Furthermore, this study suggests a potential role for FTD/TPI in chemo-preventive therapy due to its efficacy against drug-resistant (or at least 5-FU-resistant) $\mathrm{CD} 44^{+} \mathrm{CD} 133^{+} \mathrm{CSC}$-like cells at subtoxic, low doses (see Figs 2 and 3). Although further investigation is required to clarify the efficacy of this drug for tumors exhibiting 


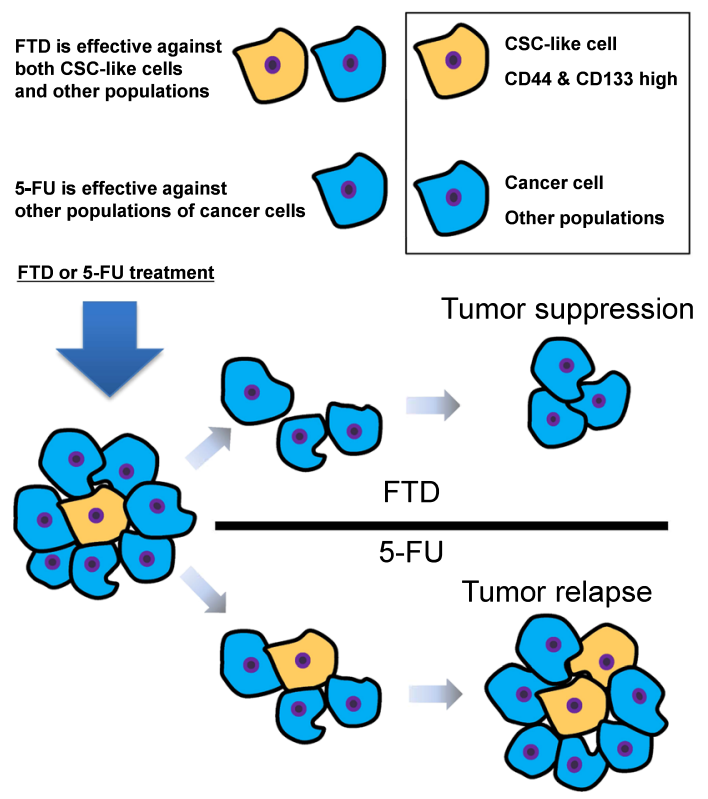

Figure 5. Schematic view of the efficacy of FTD treatment on $\mathrm{CD} 44^{+} \mathrm{CD} 133^{+}$cells. FTD is effective against cancer stem cell (CSC)-like (CD44 $\left.{ }^{+} \mathrm{CD} 133^{+}\right)$cells, but CSC-like cells show resistance toward 5-FU. FTD could be readily incorporated into the DNA of CSC-like cells. Consequently, FTD might exert an anti-sphere-forming effect on CSC-like cells, unlike 5-FU.

CSC-like properties in the clinical setting, our study indicates that FTD-based treatment might lead to improved clinical outcomes for patients with tumours exhibiting high CD44 and CD133 expression.

\section{Materials and Methods}

Cell lines and culture conditions. The DLD-1 human colon cancer cell line was obtained from the American Type Culture Collection and grown in Dulbecco's modified Eagle's medium (DMEM; Sigma-Aldrich, Tokyo, Japan) supplemented with 10\% fetal bovine serum (Life Technologies, Carlsbad, CA, USA), 100 U/mL penicillin, and $100 \mu \mathrm{g} / \mathrm{mL}$ streptomycin (Life Technologies). Cells were grown at $37^{\circ} \mathrm{C}$ in a humidified atmosphere with $5 \% \mathrm{CO}_{2}$. Cell lines were maintained as mentioned, and all lines were verified based on short tandem repeats before the study; all experimental procedures were performed using exponentially growing cells.

Chemicals. FTD, 5-FU were purchased from Tokyo Chemical Industry (Tokyo, Japan).

Cytotoxicity assay. Cell lines were seeded at a density of 2000 cells/well in 96 -well plates, precultured for $24 \mathrm{~h}$, and then exposed to FTD $(0.03,0.1,0.3 .1,3,10,30,100,300 \mu \mathrm{M})$ or 5 -FU $(0.03,0.1,0.3 .1,3,10,30,100$, $300 \mu \mathrm{M})$ for $72 \mathrm{~h}$. The in vitro cytotoxic effects of FTD and 5-FU were evaluated based on crystal violet staining. For this, cells were fixed with $2 \%$ glutaraldehyde for $20 \mathrm{~min}$, stained with $0.05 \%$ crystal violet (Wako, Tokyo, Japan) in $20 \%$ methanol for $20 \mathrm{~min}$, and rinsed with tap water; subsequently, the plates were dried on paper for $1 \mathrm{~h}$ and then $100 \mu \mathrm{L}$ of a 1:1 mixture of ethanol and $0.1 \mathrm{M}$ sodium dihydrogen phosphate was added to each well. Absorbance was measured at $595 \mathrm{~nm}$ by using an EnSpire system (PerkinElmer, Waltham, MA, USA). The FTD and 5-FU concentration that inhibited cell growth by $50 \%\left(\mathrm{IC}_{50}\right)$ was calculated from the generated regression lines.

Fluorescence-activated cell sorting (FACS) analysis of cells. To analyse and sort based on the expression of CD44 and CD133, cells were routinely cultured, harvested, digested with Accutase (Life Technologies), and resuspended in staining buffer $\left(1 \times 10^{7}\right.$ cells in $1 \mathrm{~mL}$ ), and then incubated with antibodies (mouse anti-human CD44-FITC (fluorescein isothiocyanate) and mouse anti-human CD133-PE (Phycoerythrin); Miltenyi Biotec, Bergisch Gladbach, NW, Germany) for 10 min according to the manufacturer's procedures. After staining, cells were analysed and sorted by flow cytometry using a BD FACSARIA cell sorter and a BD FACSMelody Cell Sorter (Becton Dickinson, Franklin Lakes, NJ, USA).

Sphere-formation assay. Cells were seeded into 96-well flat-bottom ultra-low-attachment culture dishes (Corning, Corning, NY, USA) at 100-500 cells/well in DMEM/F-12 serum-free medium (Life Technologies) containing $20 \mathrm{ng} / \mathrm{mL}$ h-EGF, $20 \mathrm{ng} / \mathrm{mL}$ h-bFGF (Sigma-Aldrich), 2\% B27 Supplement, and 1\% N-2 Supplement (Life Technologies) with or without FTD and 5-FU. After 14 to 40 days, the size of spheroid colonies was measured under a microscope, and colonies with a diameter exceeding $50 \mu \mathrm{m}$ were counted.

Real-time quantitative reverse transcription-polymerase chain reaction (qPCR). To assay mRNA expression, cDNA was synthesized from extracted total RNA, and then GPCR was performed using the synthesized cDNA products, ReverTra Ace qPCR RT Master Mix (TOYOBO, Tokyo, Japan), and the SYBR 
qRT-PCR Kit (Clontech, Mountain View, CA); cDNA was amplified using primers specific for TK1 (forward: 5'-AGAGTACTCGGGTTCGTGAACTT-3'; reverse: 5'-CACTTGTACTGAGCAATC-3'). GAPDH was used as a normalisation control (primers, forward: 5'-GAGTCAACGGATTTGGTCGT-3'; reverse: 5'-TTGATTTTGGAGGGATCTCG-3'). Relative expression was calculated using the CT-based calibrated standard-curve method. The calculated values were then normalised against GAPDH expression.

Dot plot analysis. Genomic DNA was purified from CD $44^{+}$CD $133^{+}$DLD- 1 spheres cultured in the presence of $1 \mu \mathrm{M}$ FTD for 11 days using the NucleoSpin ${ }^{\circledR}$ Tissue kit (MACHEREY-NAGEL, Düren, NN, Germany). Equal amounts ( $1 \mathrm{ng}$ : DLD- 1 in $2 \mu \mathrm{L})$ of denatured $(0.1 \mathrm{~N} \mathrm{NaOH}$ for $5 \mathrm{~min}$ at room temperature (RT)) genomic DNA were spotted onto a Hybond-N ${ }^{+}$blotting membrane (GE Healthcare Life Sciences, Little Chalfont, Chicago, IL, USA). The membranes were baked at $80^{\circ} \mathrm{C}$ for $2 \mathrm{~h}$, blocked with Blocking-One solution (Nacalai Tesque, Kyoto, Japan), and blotted with diluted anti-BrdU antibody 3D4 (Cat\#555627) from BD Biosciences (San Jose, CA, USA). Chemiluminescent signals were captured using the ChemiDoc ${ }^{\mathrm{TM}}$ Touch system (BIO-RAD, Hercules, CA, USA).

Statistical analysis. Statistically significant differences were identified using the Student's $t$-test as appropriate. All statistical analyses were performed using JMP Pro 9 software (SAS Institute, Cary, NC, USA).

\section{Data availability}

The datasets generated during and/or analysed during the current study are available from the corresponding author upon reasonable request.

Received: 19 February 2019; Accepted: 12 September 2019;

Published online: 16 October 2019

\section{References}

1. O’Brien, C. A., Pollett, A., Gallinger, S. \& Dick, J. E. A human colon cancer cell capable of initiating tumour growth in immunodeficient mice. Nature 445, 106-110 (2007).

2. Ricci-Vitiani, L. et al. Identification and expansion of human colon-cancer-initiating cells. Nature 445, 111-115 (2007).

3. Todaro, M. et al. Colon cancer stem cells dictate tumor growth and resist cell death by production of interleukin-4. Cell Stem Cell 1, 389-402 (2007)

4. Zeuner, A., Todaro, M., Stassi, G. \& De Maria, R. Colorectal cancer stem cells: From the crypt to the clinic. Cell Stem Cell 15, 692-705 (2014).

5. Batlle, E. \& Clevers, H. Cancer stem cells revisited. Nat. Med. 23, 1124-1134 (2017).

6. Chen, S. et al. CD133 Expression and the prognosis of colorectal cancer: A systematic review and meta-analysis. PLoS One 8, 1-9 (2013).

7. Kreso, A. \& Dick, J. E. Evolution of the cancer stem cell model. Cell Stem Cell 14, 275-291 (2014).

8. Ishimoto, T. et al. CD44 variant regulates redox status in cancer cells by stabilizing the xCT subunit of system xc- and thereby promotes tumor growth. Cancer Cell 19, 387-400 (2011).

9. Horst, D., Kriegl, L., Engel, J., Kirchner, T. \& Jung, A. Prognostic significance of the cancer stem cell markers CD133, CD44, and CD166 in colorectal cancer. Cancer Invest. 27, 844-850 (2009).

10. Wakamatsu, Y. et al. Expression of cancer stem cell markers ALDH1, CD44 and CD133 in primary tumor and lymph node metastasis of gastric cancer. Pathol. Int. 62, 112-119 (2012).

11. Yoshino, T. et al. TAS-102 monotherapy for pretreated metastatic colorectal cancer: A double-blind, randomised, placebo-controlled phase 2 trial. Lancet Oncol. 13, 993-1001 (2012).

12. Eng, C. et al. Atezolizumab with or without cobimetinib versus regorafenib in previously treated metastatic colorectal cancer (IMblaze370): a multicentre, open-label, phase 3, randomised, controlled trial. Lancet Oncol. 102, 1-13 (2019).

13. Mayer, R. J. et al. Randomized trial of TAS-102 for refractory metastatic colorectal cancer. N. Engl. J. Med. 372, 1909-1919 (2015).

14. Fukushima, M. et al. Structure and activity of specific inhibitors of thymidine phosphorylase to potentiate the function of antitumor 2'-deoxyribonucleosides. Biochem. Pharmacol. 59, 1227-1236 (2000).

15. Dallas, N. A. et al. Chemoresistant colorectal cancer cells, the cancer stem cell phenotype, and increased sensitivity to insulin-like growth factor-I receptor inhibition. Cancer Res. 69, 1951-1957 (2009).

16. Sakamoto, K. et al. Crucial roles of thymidine kinase 1 and deoxyUTPase in incorporating the antineoplastic nucleosides trifluridine and 2'-deoxy-5-fluorouridine into DNA. Int. J. Oncol. 46, 2327-2334 (2015).

17. Peters, G. J. Therapeutic potential of TAS-102 in the treatment of gastrointestinal malignancies. Ther. Adv. Med. Oncol. 7, 340-356 (2015).

18. Kitao, H. et al. The antibodies against 5-bromo-2'-deoxyuridine specifically recognize trifluridine incorporated into DNA. Sci. Rep. 6, 1-12 (2016).

19. Zhou, J.-Y. et al. Role of CD44 $4^{\text {high }} / \mathrm{CD} 133^{\text {high }}$ HCT-116 cells in the tumorigenesis of colon cancer. Oncotarget 7, 7657-7666 (2016).

20. Deng, Y. H. et al. 5 Fluorouracil upregulates the activity of Wnt signaling pathway in CD133positive colon cancer stemlike cells. Chin. J. Cancer 29, 810-815 (2010).

21. Ma, S., Lee, T. K., Zheng, B., Chan, K. W. \& Guan, X. CD133+ HCC cancer stem cells confer chemoresistance by preferential expression of the Akt/PKB survival pathway. Oncogene 27, 1749-1758, https://doi.org/10.1038/sj.onc.1210811 (2008).

22. Yeh, H.-W. et al. Pyrimidine metabolic rate limiting enzymes in poorly-differentiated hepatocellular carcinoma are signature genes of cancer stemness and associated with poor prognosis. Oncotarget 8,77734-77751 (2017).

23. Weagel, E. G. et al. Membrane expression of thymidine kinase 1 and potential clinical relevance in lung, breast, and colorectal malignancies. Cancer Cell Int. 18, 135 (2018).

24. Kim, C. G. et al. Profiling of differentially expressed genes in human stem cells by cDNA microarray. Mol. Cells 21, 343-355 (2006).

25. Shitara, K. et al. Trifluridine/tipiracil versus placebo in patients with heavily pretreatedmetastatic gastric cancer (TAGS): a randomised, double-blind, placebo-controlled,phase 3 trial. Lancet Oncol 19, 1437-1448 (2018).

26. Bekaii-Saab, T. \& El-Rayes, B. Identifying and targeting cancer stem cells in the treatment of gastric cancer. Cancer 123, 1303-1312 (2017).

27. Van Cutsem, E. et al. Abstracts. Annals of Oncol. 29(suppl_5), O-022 (2018). 


\section{Acknowledgements}

We thank the members of our laboratories for their helpful discussion. This work received financial support from grants-in-aid for Scientific Research from the Ministry of Education, Culture, Sports, Science, and Technology (to M.M. and H.I.; grant nos. 17H04282, 17K19698, 16K15615, and 15H05791) and Taiho Pharmaceutical Co., Ltd. (to Osaka University, Japan).

\section{Author contributions}

H.I. and M.M. conceived this study; K.T. conducted the experiments; K.T., M.K., J.K., T.K., and A.A. analysed and interpreted the data; K.T. wrote the manuscript; N.H., K.M., T.T., Y.D., and M.M. supervised the project. All authors reviewed the manuscript.

\section{Competing interests}

This study was funded by Taiho Pharmaceutical Co., Ltd (Tokyo, Japan), Evidence Based Medical Research Center INC. (Osaka, Japan), Unitech Co., Ltd. (Chiba, Japan), IDEA Consultants, Inc. (Tokyo, Japan), and Kinshu-kai Medical Corporation (Osaka, Japan). K.T., K.M., T.K., and T.T., are employees of Taiho Pharmaceutical Co. Ltd (Tokyo, Japan).

\section{Additional information}

Correspondence and requests for materials should be addressed to M.M. or H.I.

Reprints and permissions information is available at www.nature.com/reprints.

Publisher's note Springer Nature remains neutral with regard to jurisdictional claims in published maps and institutional affiliations.

(c) (i) Open Access This article is licensed under a Creative Commons Attribution 4.0 International License, which permits use, sharing, adaptation, distribution and reproduction in any medium or format, as long as you give appropriate credit to the original author(s) and the source, provide a link to the Creative Commons license, and indicate if changes were made. The images or other third party material in this article are included in the article's Creative Commons license, unless indicated otherwise in a credit line to the material. If material is not included in the article's Creative Commons license and your intended use is not permitted by statutory regulation or exceeds the permitted use, you will need to obtain permission directly from the copyright holder. To view a copy of this license, visit http://creativecommons.org/licenses/by/4.0/.

(C) The Author(s) 2019 